\title{
EL MUNDO POSIBLE DE LOS HÉROES MEDIÁTICOS. (Aparte del libro: Los héroes mediáticos)
}

\author{
THE POSSIBLE WORLD OF MEDIA HEROS \\ (Piece of book: The media heroes)
}

Sandra Leal Larrarte.

Docente Programa de Comunicación Social-Periodismo, Universidad del Quindío.

Fecha de recibido: Febrero 3 de 2010

Fecha de aceptado: Junio 9 de 2010

Correspondencia: Programa de Comunicación social - periodismo, Universidad del Quindío Av. Bolívar 12N \#15-00, Armenia - Quindío. Correo electrónico: salale34@yahoo.com.ar

\section{RESUMEN:}

En toda historia caben cientos de posibilidades, cada una constituye un mundo de acción. La pregunta es ¿a través de qué medios o porqué razones, los autores eligen determinada opción? Los héroes de cómic, que a pesar de sufrir críticas acerca de sus contenidos han contribuido en el engrandecimiento cultural de generaciones enteras, responden a las necesidades sociales y a los pareceres del contexto socioeconómico en el que están inscritos al momento de su ejecución. Igual pasa con nuestros héroes nacionales, productos de melodramas diversos muestran la historia del excluido y su capacidad e inteligencia para enfrentar con éxito esa exclusión de la que es víctima. Son dos tipos de héroes, para dos tipos de sociedad: una en la que ser fuerte es la clave y otra en la que no teneropciones es lo normal.

PALABRAS CLAVE: héroes, cómic, mito, mundos posibles, lector.

\section{ABSTRACT:}

In every story there are hundreds of possibilities; each one is a world of action. The question is cby what means or reasons, why the authors choose a particular option? The heroes of comics despite being criticized about their content have contributed to the cultural greatness of generations, they respond to the social needs and the views of the socioeconomic context in which are enrolled at the time of execution. Same happens with our national heroes as a product of many melodramas, they show the story of the excluded and their ability and intelligence to deal successfully with the exclusion of which is a victim. There are two types of heroes, for two types of society: one in which being strong is the key and another is that it is normal not to have any options.

Key words: heroes, comics, myth, possible worlds, reader.

\section{INTRODUCCIÓN}

No es que los héroes de cómic o de los medios masivos de comunicación tengan más publicidad que los antiguos héroes, lo que pasa es que son los nuevos héroes, representan una nueva identidad. Ellos son los mitos del último siglo que entraron reemplazar o a refigurar, los viejos fetiches que se venían repitiendo en los libros y que representaban a antiguos dioses griegos o romanos que ya no tienen representación dentro del imaginario mundial.

El mito del héroe viene desde tiempos antiguos. Homero, escritor de la Iliada y la Odisea recogió viejas historias que se divulgaron ampliamente en su tiempo y contó las vidas de héroes Divinos (Marte, Atenea, Zeus, por ejemplo) y terrenales (Aquiles, Héctor, Agamenón, entre muchos otros) cuyos actos se entrelazaron, para bien o para mal, en la Guerra de Troya.

Entre los nórdicos se destacan las Eddas, donde se recogen las principales historias de los mitos islandeses, en los que aparecen por primera vez (al menos en el ámbito escrito) los dioses Odin y Thor, a quienes quizá ya no se les reza, pero cuyas representaciones alimentan la imaginación de muchos hoy en día.

No es posible saber qué discutían los ancestros humanos alrededor de sus hogueras, pero si se admite la necesidad colectiva de tener referentes vivos que ofrezcan ejemplo y fuera de eso le demuestren al ser humano común y corriente que existe la esperanza, que es posible ser superior a las fuerzas naturales y a las no naturales, es prudente afirmar que ellos crearon los héroes extrayéndolos de entre su propio grupo y cuando no lo había pues no dudaron en inventarlo, recurriendo a esa habilidad tan nuestra de crear sueños posibles que al ser compartidos adquieren visos de realidad.

Como las creaciones culturales humanas, la del héroe es una creación que se adapta a su tiempo, emerge de él, de sus necesidades, de su idiosincrasia, de sus problemas y al salir a la luz pública es adoptado por todos para bien de sus espíritus; pero, en el caso del mundo mediático que se desarrolló desde mediados del s. XIX con la industrialización del periódico y que ha pasado por evoluciones tecnológicas como la radio, la televisión y ahora el Internet (que son cada vez más abarcadoras de la producción cultural Ilevándola a la globalización), el surgimiento de nuevos héroes, convertidos en mitos mediáticos, se dio para beneficio de los bolsillos de sus creadores.

Por primera vez asistimos a una comercialización de la figura del héroe. Ese ser superior, un semidios salvador, casi humano pero mucho mejor, es ahora un producto 
consumible. Mientras con el semidiós Hércules -hijo del padre de todos los dioses, Zeus, quien por la envidia de su hermano Ares bebió del agua de la mortalidad pero conservó el poder de su brazo que lo hacía indestructible-, para sus seguidores era suficiente con revivir sus hazañas cada vez que a algún trovador le daba por contar su historia, repetida una y otra vez sin mayor variación; pero mientras la historia de Hércules es repasada, a Supermán le toca reinventarse todos los días para ser efectivo.

En el siglo XX no se puede tener contento al público. La gente, ávida de historias -pues como ser narratológico que es las busca en todas partes-, no se siente feliz con la misma narración una y otra vez. Con las comunicaciones vía satélite una vez el trovador televisivo o radial o multimediático cuenta en una primera ocasión su creación mítico-herórica todos la escuchan o la leen casi al mismo tiempo y por lo tanto, el milagro de antaño en que todos se recreaban con la misma historia una y otra vez tan sólo deleitados en la variación de la manera en que fuera contada, ya no funciona. La historia original prevalece como argumento, pero los acontecimientos tienen que variar.

Dejando aparte las críticas a la industria cultural, que aunque tengan algo de validez tienen mucho de obcecación sobre todo cuando estos críticos ignoran deliberadamente que si bien es cierto que los productos mediáticos masifican el mensaje, este llega de manera individual y es consumido de acuerdo a los campos de recepción ${ }^{2}$ en que se desplaza el receptor, lo que genera involuntariamente al emisor una diferencial de recepción que permite que el nuevo mito sea adaptado a los problemas del espectador a pesar de la distancia social, cultural y política del mensaje que recibe.

Esto hace factible que Supermán sea entendido en todas las culturas, o que Batman sea un héroe gótico, apolítico, atento a la diversidad, tolerante, algo sórdido, que encanta por su visión casi siniestra de la vida (la cual nunca ha sido bien manejada por sus autores), pero que llama la atención.

\section{EL HÉROE LATINO}

Si nos acercamos al ámbito latinoamericano, se debe admitir que los héroes creados por los medios están hechos a su medida. Son más humanos, más normales, menos poderosos, menos ricos, menos tecnificados, sin secretos militares (pero sí de otros tipos), sin doble identidad, pero igualmente superiores en su forma de actuar.

Dos ejemplos de héroes locales que se pueden analizar son Betty La Fea, extraída de una telenovela (entendiendo esta como la expresión popular más influyente dentro de la comunidad latina) y al personaje animado El Profesor Super $O$ que aparece en las emisiones de un canal de música, como el que más encaja actualmente dentro de los discursos de los adolescentes y adultos jóvenes.

Si se hace marcha atrás para recobrar mitos locales, es forzoso hablar del temible dios Bochica el cual no tuvo ningún escrúpulo en inundar la tierra de los Chibchas para demostrarles su poder y volverlos a poner en el camino de la rectitud del cual se habían separado (una versión local del mito bíblico de Sodoma y Gomorra, que los Chibchas ya había recreado mucho antes de que llegaran los evangelizadores). Cuenta el mito que luego de un tiempo de verlos sufrir y de notar su arrepentimiento, dicho dios regresa para horadar una piedra con una especie de varita mágica por donde se canalizan las aguas y se crea el bellísimo, pero hoy descuidado, Salto del Tequendama.

Un poco más mundano, pero definitivamente un héroe más real y cercano históricamente, sería Simón Bolívar, el Libertador, cuya vida es casi reverenciada en Venezuela. Su ejemplo acompaña las historias de acciones militares como las del general Santander o el general Córdoba, entre muchos otros próceres. No obstante su importancia histórica, es precisamente por ese hecho (el de pertenecer a los libros de historia) que las últimas generaciones casi lo desconocen por considerarlo más como un ente destinado a permanecer en libros llenos de erudición que en la vida social de los individuos que lo precedieron.

Las historias del Libertador, llenas de ejemplos de valentía y superación, nunca han alcanzado el nivel de mito porque no se les permitió a los autores recrearlo para el consumo popular, nadie dentro de una reunión familiar o entre amigos comenta las hazañas de Bolívar con la libertad y la pasión que comentan el último film de los Hombres $X$., porque precisamente su imagen no evolucionó, murió junto con él y se convirtió en un recuerdo, mientras que los héroes de la Liga de la Justicia, o la imagen de Betty La Fea recorren el público contando nuevas formas de enfrentar los sufrimientos que el mundo les depara.

En Colombia tenemos muy pocos héroes: Betty La Fea se puede considerar una, de pronto Pedro El Escamoso, quizá Méndez el protagonista de la telenovela Hasta que La Plata nos Separe en la que el personaje aparece como un remedo cómico del hombre de extracción popular pero con muchos arrestos para enfrentar un universo que le es contrario, y en última instancia, como un héroe que emerge aparece el cómic animado El Profesor Super $O$, quien todos los días se debate en una lucha casi perdida contra la ignorancia ortográfica.

Según la docente de comunicación social Ana Cecilia Cervantes (2005), quien lanzó un estudio alrededor del fenómeno de las telenovelas en Colombia, estas producciones televisivas atraen como una forma de identificación social.

\begin{abstract}
"La búsqueda de reconocimiento es lo que acerca al gran público de la telenovela a sus historias y sus personajes. Ellos conforman grupos marginados por una sociedad que los excluyó cuando se hacinaron en las zonas más apartadas de los centros de poder, mucho antes de la creación de los estados; y han encontrado en la telenovela su propia imagen: la de unos seres excluidos de la sociedad por su condición socioeconómica, etnia o género" (Cervantes, 3; 2005).
\end{abstract}

${ }^{2}$ CAMPOS DE RECEPCIÓN: de acuerdo al mexicano Diego Lizarazo Arias (Lizarazu, 1998; 106) "los actores sociales no abordan los mensajes de los massmedia de manera aislada o atomizada. Se encuentran localizados en espacios sociales y pertenecen a clases o grupos multifactorialmente reconocidos. Pero, en tanto las condiciones sociales (pertenecer a una u otra clase) no son disposiciones absolutamente finalistas (destinos totalmente inevitables), los agentes.... son capaces de desplazarse transversalmente de unos campos a otros y desbordar sus codicionamientos de clase. Esto es, participan simultáneamente en múltiples campos, en los cuales desarrollan estrategias y desplazamientos para modificar (según las posibilidades del juego) sus condiciones de vida". 
Si se acepta su tesis de que la telenovela es la expresión de una sociedad escindida, construida desde el sentir de la exclusión, se entiende que los héroes que produce sean seres marginados de la normalidad social, personas no muy agraciadas, pobres e incluso intelectuales venidos a menos que deben enfrentar un mundo lleno de estereotipos en los que no logran encajar.

Contrario a sus homólogos norteamericanos o europeos, jamás tendrán un desfile en su honor, nadie se pondrá camisetas con sus escudos, ni siquiera tienen escudos que los identifiquen, ningún niño les dirá: "cuando grande quiero ser como tú"; porque, y he ahí la genialidad de su existencia, ellos somos nosotros. Todos tenemos un poco de ellos, representan nuestra vida de perdedores, de don nadie, mientras que los héroes extranjeros representan la posibilidad de ser más, de ser grandes y geniales, de ser queridos por todos, quizás los foráneos sean un poco más utópicos, pero son igualmente amados.

\section{EL MUNDO PARALELO DE LOS SUPERHÉROES}

¿En dónde vive Supermán? En Metrópolis. ¿En dónde vive Batman? En Ciudad Gótica. ¿En dónde entrenan los X-Men? En la Mansión X. ¿En dónde trabaja Betty La Fea? En Colombiamoda. ¿En dónde desarrolla su lucha el Profesor Super O? En el planeta Mojarra con Plátano.

Todos viven en ciudades, planetas o en empresas que no existen, por lo menos en nuestro sistema social de referencia. El mundo de los héroes es parecido, pero en un contexto ajeno al nuestro, pertenecen a mundos paralelos creados precisamente para que la realidad de su existencia sea tolerada. Porque en nuestro entorno a Betty nunca la hubieran contratado, no por fea sino porque no se sabía vestir apropiadamente para la clase de empresa en la que debía laborar; a Supermán no le permitirían volar por los cielos de Bogotá o Nueva York porque podría confundir los radares de los aeropuertos y generar una colisión; a los $X$ Men no les haría falta usar sus talentos porque no tendrían tantas ocasiones para hacerlo en una realidad más tranquila como la que vivimos (a pesar del conflicto, pues la posibilidad de encontrarse con un delito mientras ocurre es de menos del $20 \%$. Un policía normal cada cuanto podría salvar a una anciana de una pandilla, rescatar a un grupo de rehenes, o enfrentarse a un gangster y a un supervillano, todo en el transcurso de una semana o menos). Con esto en mente se explica la necesidad de que vivan en mundos alternos.

Lo cierto es que ellos viven en lo que literariamente hablando se reconoce como Mundos Posibles ${ }^{3}$, que son construcciones de mundos fantásticos que le permiten al lector o televidente hacer una previsión de sus posibilidades de existencia y crea un acuerdo tácito con el receptor para aceptar la nueva realidad que se le propone.

"A mí me gustaba mucho leer una columna de EI Tiempo que se llamaba Rosario de Perlas de Alfredo Iriarte y me encantaban las correcciones que se hacían a errores comunes y a otros no tan comunes del lenguaje. De allí me nacieron las ganas de hacer algo, pero que no fuera solo mostrando el error sino creando un universo para contar esto de manera entretenida y que le llegara a todo el mundo",

Martín De Francisco, creador del Profesor Super O, en una entrevista que se publicó en la página de Colombia Aprende (Colombia Aprende, 2006; www).

Así como lo manifiesta Martín De Francisco, creador del concepto del personaje del Profesor Super O, lo mismo debió pasar por las mentes de los creadores Joe Shuster y Jerry Siegel en 1938 para concebir a Supermán, o de Jack Kirby y Stan Lee para hacer los X-Men en 1963. Sabían que no podrían colocar a sus personajes en el mundo en que ellos mismos se desempeñaban porque no sólo no iban a resultar creíbles, sino porque los imposibilitarían de realizar muchas de sus hazañas. Cómo podría Supermán detener a todo un tren sin que nadie resultara herido al romper la ley de la inercia, pues si alguien en nuestro mundo detiene un tren bala de un solo golpe llevándolo de 300 kilómetros por hora a cero, causaría cientos de muertes por no decir de la destrucción total del aparato. O cómo podría el Profesor Super $O$ desplazarse en un "escalúmelo acuático" a la fabulosa distancia de "tres ceviches de camarón con dos plátanos verdes", cuando tales medidas no existen en nuestro mundo.

Una de las características de la creación de Mundos Posibles es que el autor tiene el permiso creativo de amoblar su mundo con un limitado número de personajes que se construyen con la adición de propiedades y sus combinaciones, apunta Eco en su libro Lector In Fabula (1987). Así el creador no tiene que molestarse con la entrada y salida continua de diferentes personajes, porque si hay un número predeterminado de individuos por historia, cada uno con sus propias características que los hace únicos y le permiten al escritor o guionista concentrar la acción en ellos sin tener que dispersarla en los acontecimientos que rodean a otros.

Lo anterior facilita que con historias tan complejas y dotadas de tantos personajes como la de los X-Men se pueda crear una continuidad de historias, cada una con personajes distintos, pero nunca con todos al mismo tiempo.

Los mundos posibles se construyen con el cruce de tres mundos que son importantes a la hora de interpretarlos: el Mundo Real de Referencia o Wo, el Mundo Posible que afirma el Autor o Wn y el Mundo Posible que imagina el lector o Wr, los cuales están presentes en todas y cada una de las obras imaginadas (en general en el mundo de las ideas) y son inseparables.

3 MUNDO POSIBLE. Según el semiólogo y novelista Umberto Eco (1987; capítulo VIII): "Un mundo posible es una construcción cultural donde los individuos se construyen mediante la adición de propiedades y sus combinaciones. De esa manera, Caperucita Roja, dentro del marco de la historia que la construye, no es más que la coagulación espacio-temporal de una serie de propiedades físicas y psíquicas. El mundo narrativo toma "prestadas" propiedades del mundo real y recurre a individuos reconocibles a quienes no necesita reconstruir propiedad por propiedad. El texto presenta los individuos mediante nombres comunes o propios. Un mundo posible no es autónomo, se superpone al mundo real de la enciclopedia del lector". También reconoce que el mundo "real" de referencia es una construcción cultural que se debe de tomar en cuenta a la hora de elaborar las interpretaciones que hace el receptor, con esto en mente se entiende que para cada realidad en que se desenvuelve el receptor habrá una lectura de ese mundo posible al que se refiere el autor

Rev. Invest. Univ. Quindío (20): 72 - 77. Armenia - Colombia 


\section{MUNDO POSIBLE DE SUPERMÁN}

Así se tiene que en la historia de Supermán el mundo de referencia en que fue creado originalmente era el de la preguerra, en 1938 Hitler comenzaba a hacerse notar en Alemania, mientras que en Estados Unidos estaban apenas superando el gran shok que les causara la depresión económica y la gran caída de la bolsa en 1929 cuando muchas familias acaudaladas y empresas de tradición perdieron sus capitales; la sociedad estaba tratando de reagruparse y encontrar algo que les diera esa esperanza que la pobreza repentina les había quitado. Desde el plano de lo académico y filosófico se estaba haciendo una reinterpretación de la idea de Superhombre que proponía Nietzche.

Bajo este marco histórico aparece el Hombre de Acero, un hombre con dos personalidades: una secreta y una pública (mundo posible que afirma el autor), donde la primera, la de Clark Kent representa al hombre del común honesto y obligado a trabajar para sobrevivir, pero que a pesar de vivir en la sombra es feliz con lo que hace, mientras que su alter ego Supermán es un hombre público, invencible y tremendamente poderoso capaz de enfrentarse a lo que sea con tal de cumplir con sus ideales de libertad y de justicia, resumidos en su grito de guerra: "I luchar por la justicia!" Después de 48 años en los que varias generaciones crecieron con un Supermán gentil y bonachón, un poco ingenuo quizá, cambia en 1986 cuando durante la crisis de los cómics de los $80^{4}$ el personaje es vendido a otra casa editorial y su historia es reconstruida sutilmente para que se ajuste a los nuevos tiempos. Es entonces que el Hombre de Acero se transforma en un ser más complejo, dominado por su impotencia frente a la realidad que lo rodea, descubre que ser fuerte no lo es todo. Su enemigo no es un Lex Luthor científico, sino un empresario que no es tan evidente en sus villanías. Siendo así, esta construcción argumental se convierten en el mundo posible que afirma el autor y sobre el cual se trabaja para continuar la historia.

Los lectores de Supermán han encontrado en él la afirmación de un sueño universal: cualquier persona puede ser y es más de lo que aparenta (mundo posible del lector). Y con esta certidumbre los seguidores se enfrentan mensualmente en el caso de los cómics, o de década en década a las películas de este superhéroe, para ver tan sólo como el humilde Clark Kent sortea su vida llena de debilidades para ser reemplazado por esa parte de él que es invulnerable y capaz de enfrentar cualquier cosa.

\section{MUNDO POSIBLE DE BATMAN}

En el caso de Batman, también hay dos mundos de referencia similares a los de el Hombre de Acero. Nacido de la pluma creativa de Robert Kane, el Hombre Murciélago aparece un año después de Supermán, 1939. También ligado a la realidad de un mundo a punto de entrar en la Segunda
Guerra Mundial en el cual los avances científicos no parecían ofrecer prosperidad sino fortalezas para el enfrentamiento bélico, donde la pobreza de la comunidad había degenerado en el aumento de la delincuencia y, en definitiva, en un mundo de referencia en el que el optimismo no parecía tener cabida.

Si no hay espacio para el optimismo, tampoco lo había para una ciudad soleada como Metrópolis, entonces aparece Ciudad Gótica, donde todo es más sombrío y duro (mundo posible que presenta el autor). Pero, también donde un hombre solo y sin poderes demuestra que con su habilidad técnica y su inteligencia pueden contra las adversidades que le presenta el mundo (mundo posible del lector). Quién no quisiera tener la fortaleza de ese hombre que al perder a lo que más amaba en el mundo, sus padres, debe crecer solo en una gran mansión, rodeado de lujos pero con el respetuoso cariño que le ofrecía su estirado criado Alfred. Bruce Wayne es un hombre que a través de la autodeterminación y la autodisciplina decide tomarse la justicia por sus propias manos y vengar no sólo la muerte de sus padres, sino que asume la titánica tarea de tratar de dominar el crimen.

En la reactivación de su historia en la década de los 80 , el Hombre Murciélago no tuvo tanta suerte como su antecesor Supermán. Su compañero de aventuras, Robin, muere durante una explosión en un capítulo que fue fuertemente criticado por los seguidores de la serie y fuera de eso, en 1993 cuando se enfrenta al supervillano Bane pierde la batalla y queda inválido, por lo que su capa (símbolo de su carácter) es recogida por el estudiante de una liga secreta Jean Paul Valley quien se convierte en el Señor de la Noche (mundo posible que presenta el autor). Con la diferencia de que al ser curado y recuperar la movilidad de sus piernas, Bruce Wayne (la personalidad secreta de Batman) acepta que él siempre quiso ser el Hombre Murciélago y que su alter ego no es una imposición del destino, como lo fue al principio de su carrera. De este modo se le dice al lector: no importa cuántas adversidades tenga, el mundo será benigno con usted siempre y cuando abrace con amor su destino (mundo posible del lector). Una actitud muy de la Nueva Era.

\section{MUNDO POSIBLE DE LOS X-MEN}

Un caso que merece mención aparte es el de los X-Men. Pertenecientes al Universo Marvel, una marca reconocida a nivel mundial por crear historias de grandes héroes como $\mathrm{El}$ Hombre Araña, El Hombre Increíble y Los Cuatro Fantásticos, cuya principal característica es tener héroes no necesariamente anónimos (salvo el Hombre Araña y el Hombre Increíble, ningún otro tiene doble identidad), pero sí con una lucha interior. El Hombre Araña debe enfrentar el dolor de haber permitido la muerte de su tío, de quien siempre le quedará el último consejo que le dio: "un gran poder conlleva una gran responsabilidad", el cual queda como sello filosófico del Universo Marvel.

\footnotetext{
${ }^{4}$ CRISIS DE LOS CÓMICS. Después de un increíble boom de ventas, donde empresas como la Marvel Comics y DC Comics alcanzaban a vender hasta 40 millones de ejemplares mensuales alrededor del mundo, una crisis económica mundial y quizás el cansancio de los lectores de ver las mismas historias con los mismos personajes una y otra vez, sus ventas descienden a 11 millones de ejemplares lo que obliga a las empresas a refrescar sus historias y sus personajes. Pero, para no hacerlo tan bruscamente, los aficionados de las historias más reconocidas tuvieron la suerte de saber qué pasaba con sus personajes pues primero crean una historia de relevo que explique el cambio. Mientras que con historias menos importantes este relevo jamás se dio y los lectores tuvieron que imaginarse la transición.
} 
En el caso de Los Cuatro Fantásticos deben buscar un equilibrio entre lo que son frente a lo que quieren ser, especialmente La Mole. El Hombre Increíble, lucha contra sí mismo todos los días para permanecer como el doctor David Banner y no ser Hulk, ese musculoso hombre verde de quien no está seguro, pues al no recordar lo que le pasa como Hulk, Banner vive con el dolor de creer que él fue quien mató a su esposa Sussie. $Y$ los $X-M e n$, personajes nacidos con el gen $X$ que los dota de poderes especiales, pero que les quita la oportunidad de ser normales y pertenecer a la comunidad en igualdad de condiciones (mundo posible que presenta el autor).

Los X-Men nacen en 1963 en medio de las luchas raciales que libraban dos importantes líderes de las negritudes, como fueron Martín Luther King y Malcom X (mundo de referencia). Ambos buscaban que se tratara en condiciones de igualdad a la comunidad negra norteamericana, la cual había vivido hasta ese momento en condiciones de opresión y segregadas socialmente, pero el reverendo Martin Luther King quería conseguir esto de forma pacífica, mientras que el líder recientemente convertido al islamismo, Malcom $X$ apoyaba la violencia e impulsaba a las comunidades negras a considerarse superiores mientras que acusaba a los blancos de ser una raza inferior, un subproducto de la evolución humana.

Así aparecen en la historieta dos líderes diametralmente opuestos, el Profesor Xavier dueño de la Mansión X y director de la escuela donde estudia su grupo los X-Men, y Magneto, un judío sobreviviente del holocausto nazi quien acusa a los humanos que no portan el gen $\mathrm{x}$ de estar atrasados evolutivamente (mundo posible que presenta el autor).

La historia de estos héroes mutantes es la representación de las luchas raciales en Estados Unidos, pero en términos más generales es la historia de la diferencia (mundo posible del lector). Todos somos diferentes en alguna medida frente a nuestros congéneres, eso llena al mundo de infinitas posibilidades, pero también hace que en ocasiones esa diferencia marque a alguien negativamente y haga sentir a quien la posee que no pertenece al grupo en el que se moviliza y lo lleve a apartarse, pero más que eso, es posible que lo lleve a pertenecer a sub grupos sociales que políticamente o ideológicamente no están alineados con el de la mayoría.

\section{MUNDO POSIBLE DE BETTY LA FEA}

Quién es Betty La fea. Betty Pinzón, nacida de la pluma del libretista colombiano Fernando Gaitán rodada entre 1999 y 2001 se convirtió pronto en una novela tipo exportación para todo el mundo. Hasta ahora se han hecho versiones en casi 32 países donde también logró el éxito. Betty la fea, fue producida durante el gobierno del presidente Andrés Pastrana Arango recordado entre otras cosas por la aplicación del Plan Colombia del que se ha hablado tanto y se expone como una intromisión del gobierno de Estados Unidos en Colombia, así como de la desvalorización del Producto Interno Bruto del $20 \%$ lo que contribuyó no sólo al aumento del desempleo (considerado en un 16\%) sino al fracaso de muchas empresas (mundo de referencia).

Entonces, ésta telenovela de fama internacional es una representación de unos colombianos sumidos o cercanos a la pobreza (se calculaba en esos momentos que el $60 \%$ de los nacionales recibían ingresos que de acuerdo a los cánones internacionales los catalogaban como pobres). En Colombia aproximadamente hay 42 millones de personas, de las cuales cerca de 22 millones están edad laboral los cuales están expuestos a una escasa oportunidad de empleo, lo que los lleva a ofrecerse para cualquier cargo o hacer cualquier cosa con tal de mantener la poca oportunidad laboral que el medio les da y, fuera de eso, es la muestra de una Colombia corrupta donde los dueños de empresas hacen cualquier cosa por mantenerse en la cima. Así aparece esta economista de altos valores intelectuales, pero de apariencia descuidada y poco agraciada que es contratada por un gigoló recientemente nombrado como director de una empresa de modas que debe demostrar su capacidad, sin importar cómo (mundo posible que presenta el autor).

Con éstas referencias los colombianos acudieron en masa a las pantallas durante los más de 300 capítulos que se transmitieron, todo con tal de verse reflejados en ese cuento de hadas donde una mujer fea pasa a ser hermosa, y cual si fuera una Cenicienta termina casándose con el príncipe a pesar de los malos tratos que este le prodigó y los problemas que le ocasionó (mundo posible del lector). Es una prueba más de cómo los mundos posibles son la representación de todo aquello que soñamos se hagan realidad. Betty la fea es la utopía del ser humano promedio, del personaje común reflejado en la pantalla.

\section{MUNDO POSIBLE DEL PROFESOR SÚPERO}

En un continente que cuenta con casi 40 millones de analfabetos, lo que representa un $27 \%$ de la población total, de los cuales casi la mitad de ellos no se reconocen como analfabetos totales, pues saben leer y escribir pero no lo practican. Además hay que reconocer otros tipos de analfabetismo que tienen que ver con la capacidad de entender el mundo y de extenderse en su conocimiento a través de la lectura, en ese caso estamos peor, pues tan sólo cuatro de cada diez prefieren leerse un libro a verse una película (mundo de referencia).

Ese es el panorama en que el Profesor Super $O$, debe enfrentar todos los días para bajar los niveles de ignorancia "tan sólo un poquitico". Él, como cualquier superhéroe que se respete recibió sus poderes de una forma casi mágica y sin pedirlos, pues fue su abuelo quien se los otorgó luego de que él sufriera un accidente, desde entonces se dedica a resolver los entuertos idiomáticos donde quiera que se presenten (mundo posible que presenta el autor).

Aunque su presencia en los medios es netamente educativa, no elimina ese poder de entretenimiento que estos tienen y a través del descubrimiento de cómo se mueve el mundo en el planeta Mojarra con Plátano los adolescentes que ven el Canal 13 descubren cuál es la forma correcta de conjugar el verbo concienciar o si se dice "visitar Paris" o "visitar a Paris" (mundo posible del lector). No se puede decir que ver al Profesor Super $O$, criticando la pronunciación o la conformación de las oraciones lleve al espectador a la catarsis, pero sí le ayuda a identificarse con la idiosincrasia de los habitantes de su país. 


\section{CONCLUSIÓN}

Los héroes mediáticos no sólo son creados para resignificar el mundo que los rodea, sino que son los llamados a recalificar la heroicidad de otros tiempos, su cualidad no es la de ser salvadores del mundo porque ya está muy claro de que no hay quien lo salve, pero sí están llamados para hacernos entender quiénes somos y que la lucha no es en contra de otros, sino frente a nosotros mismos.

Está claro que su presencia es un reflejo de la identidad individual y grupal, que están destinados a ayudarnos a entender cómo encajamos nosotros en las situaciones que nos rodean. Pero la pregunta que se debería responder es: ¿los necesitamos? Y si es así, ¿cuánto los necesitamos y para qué? ¿Cómo reflejan la identidad de su medio social? Y por último, ¿por qué nuestros héroes tienen que ser pobres, feos y casi ridículos, mientras los de las naciones industrializadas, son poderosos, extremadamente bellos y sin problemas monetarios?

\section{BIBLIOGRAFÍA}

Accorsi, Andrés. 2006. Entrevista a Stan Lee. [En línea] Publicado en Tebeosfera. Disponible en: www.tebeosfera.com [Consulta: 2005, junio 17]

Albert Galera, Josefina. (1994) “Los componentes ficcionales del relato”, Universitat Rovira i Virgili. Mundos de Ficción, vol. 1. 1994. Actas del VI Congreso Internacional de Semiótica. Editado por la Universidad de Murcia.

Aquino, María del Pilar. 1992. Nuestro clamor por la vida. Editorial del, San José - Costa Rica.

Barbieri, Danielle. 1989. El lenguaje del cómic. Ed. Paidós, colección Instrumentos. Barcelona - España

Bueno, Mónica L. 1994. “Utopía, Ficción y Literatura: los Mundos Posibles”, Mundos de Ficción, vol. 1. 1994. Actas del VI Congreso Internacional de Semiótica. Universidad Nacional de Mar del Plata - Argentina. Editado por la Universidad de Murcia.

Cervantes, Ana Cecilia. 2004. La telenovela colombiana: un relato que reivindicó las identidades marginadas. Ed. Universidad del Norte, Barranquilla-Colombia.

Corro, María Nieves. 2005. ¿Cómo venden los dibujos? [En línea] Disponible en: www.istmoenlinea.com.mx [Consulta: 2005, Junio 20]

De la Incera Hernández, Nadiosly de la C. y otros. 2006. Apuntes acerca de la teoría de las representaciones sociales. [en línea] disponible en: www.monografias.com

Di Santis, Paulo. 2004. La historieta en la edad de la razón. Ed. Paidós Comunicaciones. Buenos Aires - Argentina.

Dorfman, Ariel; Mattelart, Armand. 1972. Para leer al Pato Donald. Siglo XXI Editores. México - México.

Dumezil, George. 1990. El destino del guerrero. Ed. Siglo XXI Editores, México D.F. - México.

Eco, Humberto. 1987. Lector In Fabula. Editorial Tusquets, Barcelona.

Eco, Umberto. 2004. Apocalípticos e integrados ante la cultura de masas. Tusquets, Barcelona.

Estramiana, Alvaro y otros. 2006. Representaciones sociales de la mujer. Publicado por la Universidad Complutense de Madrid, revista Athenea digital [en línea] disponible en: http://antalya.uab.es/athenea/num9/alvaro.pdf

Gasca, Luis; Gubern, Roman. 1988. El discurso del cómic. Editorial Catedra, serie Signo e Imagen. Madrid-España.

Lizarazo Arias, Diego. 1998. La reconstrucción del significado. Ed. Addison Wesley Logman, México D.C.

Pérez Sedeño, Eulalia. 2000. ¿El poder de una ilusión?: ciencia, género y feminismo. Ediciones Universidad de Salamanca.

Tauber, Elizabeth. 2003. Género y Poder. Editorial Uma, Buenos Aires - Argentina. 